Article

\title{
Forensic Behavioral Science of Serial and Mass Murder with an Addition of Leisure Research: A Descriptive Synthesis
}

\author{
D J Williams ${ }^{1,2}$ \\ 1 Department of Sociology, Social Work, \& Criminology, Idaho State University, 921 S 8th Ave, \\ Pocatello, ID 83209, USA; djwilliams@isu.edu \\ 2 Center for Positive Sexuality, Los Angeles, CA 91507, USA
}

Received: 27 January 2021; Accepted: 15 March 2021; Published: 18 March 2021

check for updates

\begin{abstract}
Prevalence rates of multiple homicide are statistically rare and vary across nations, yet such cases create substantial suffering for victims and can generate widespread fear among the general population. Despite extreme rarity, it remains important for forensic experts and professionals to be prepared when extremely violent events occur. This review summarizes contemporary behavioral science of serial and mass murder, then highlights the application of recent leisure research to add new motivational and behavioral insights. Research on the application of leisure science to homicide research is in its infancy, yet in conjunction with other related behavioral science disciplines, appears to hold promise in understanding, and perhaps helping to prevent, future violence.
\end{abstract}

Keywords: forensic behavioral science; leisure; mass murder; multiple homicide; serial murder

\section{Introduction}

Forensic behavioral science draws from an array of disciplines, including psychiatry, psychology, sociology, and anthropology, to understand human behavior as it relates to legal (often criminal) matters. Although the proliferation of knowledge in recent decades has led to increased specialization within disciplines, for example the emergence of criminal psychology (direct focus on criminal behavior) from forensic psychology (focus on civil and criminal issues), the breadth of a multidisciplinary forensic behavioral science approach remains valuable in accounting for the complexity of occurrences and processes of unlawful behavior within various social and cultural environments. Social and behavioral science disciplines have their own empirical and theoretical literatures pertaining to crime, yet a basic familiarity across these literatures can help both academics and professionals to better understand, prevent, and solve cases of violent crime.

This descriptive review summarizes the behavioral science literature on serial and mass murder before highlighting emerging research on the application of leisure science, as a specific discipline, to cases of multiple homicide. Leisure science has roots in social psychology and sociology. The field currently draws from multiple disciplines, including anthropology, biology, psychology, and sociology, to understand behavior that is intrinsically motivated and relatively freely chosen [1]. Thus, leisure scholars utilize quantitative and qualitative research methods to address the who, what, when, and why pertaining to experiences that are personally enjoyable and meaningful. Such experiences that violate established laws may thus be considered leisure by violators. Although homicide experts have long known that many serial homicide offenders greatly enjoy planning and committing crimes, the application of robust leisure theory to understand details of how and why is very recent [2]. 


\section{Contemporary Behavioral Science of Serial and Mass Murder}

\subsection{Definitional Issues}

Serial murder involves the killing of individuals (usually one victim) across separate events, whereas mass murder is the killing of multiple individuals in the same event [3]. However, scholars do not agree on precise definitions of either. Regarding serial murder, experts differ on the number of victims required to establish a series, evidence (or not) of offender personal gratification, and the necessity and length of a psychological "cooling off" period between homicidal episodes [3,4]. However, a recent study utilizing a series of multinomial regression analyses found that offenders with two victims differed significantly from those with three or more victims in terms of motive and crime scene behaviors, thus three victims is the minimal number in accurately defining serial murder, though offenders with eight or more victims are particularly prolific [5].

Defining and measuring mass violence have also been problematic. Generally, the term mass violence involves victimization that results in multiple deaths and/or injuries [6]. Specifically, there are differences in mass murders (focus on number of fatalities), compared to mass shootings (gun used as weapon, fatal and/or non-fatal victimization), and situational types of mass violence such as public or private [6]. Different forms of mass violence reflect different behavioral features. For example, privately occurring familicides have very different motives and social and behavioral characteristics than attempted or completed public mass murders. Just as there has been variation in definitions of serial murder pertaining to minimal numbers of victims, there also are disagreements among experts pertaining to minimal numbers of victims required in mass murders $[3,6]$.

\subsection{Common Myths}

The phenomenon of serial murder has fascinated the public and for decades has been a staple in pop culture. However, widespread visibility of serial murder in pop culture, in comparison to relatively sparse scientific research on the topic, has led to the proliferation of myths. Common myths of serial murder, summarized in reviews by Hickey and colleagues, $[7,8]$ include the following:

* Nearly all serial murderers are Caucasian (Fact: 20\% are Black; 50\% in recent years).

* Nearly all are male (Fact: Approximately $17 \%$ are female).

* All serial murder is sexually motivated (Fact: Lust is a motivator in many, but not all).

* Serial murderers are highly intelligent (Fact: Most possess average intelligence).

* Most cannot stop killing (Fact: Many have stopped for significant lengths of time).

* Most want to be caught (Fact: There is no evidence to support this).

* Serial murderers have a prototype (Fact: They vary on numerous attributes).

There are also common myths concerning mass murder, perhaps most notably that the perpetrator suddenly "snaps" without warning and kills in a sudden rage [9]. However, the reality is that the vast majority of mass murders involve careful planning and preparation over a considerable length of time, often several weeks or months [9]. Although recent evidence suggests an uptick in incident prevalence [10] and casualties per incident [11] of mass murder in the USA, such data on mass violence have remained stable over several decades despite an exponential growth in incident reporting by the media [9]. In contrast to serial murder, where far more cases occur within the USA per capita compared to other nations, mass murder occurs with more frequency, though still statistically rare, across many nations [8]. A history of mass and spree murder in Canada, for example, reported only 66 cases from 1828 to 2012 [12]. More broadly, a study by the Crime Prevention Research Center on mass public shooting frequency from 2009 to 2015, comparing USA and Canada to European nations, found that Macedonia had the highest rate ( 0.471 per million people) followed by Albania ( 0.360$)$ and Serbia (0.281), while Germany had the lowest rate listed (0.013) [13]. 


\subsection{Core Biological, Neuropsychiatric, and Psychological Issues}

Like all behavior, extreme violence seems to be rooted in complex intersections of biological, psychological, and socio-cultural factors [14-16]. Recent research reviews in the field of behavioral genetics suggest that a propensity for extreme violence, such as homicide, is associated with polymorphisms that involve the detection, transportation, and catabolism of neurotransmitters, particularly dopamine and serotonin, that are manifest within adverse environments (such as family dysfunction) $[17,18]$. This genetic evidence is sufficiently strong that a court subsequently reduced a jail sentence for an offender convicted of homicide [19]. However, polymorphisms underlying extreme violence (i.e., MAOA, DRD4, 5HTTLPR, and COMT) are particularly associated with impulsive and antisocial behavior $[17,18]$, which traits are often reflected in single homicides but less so with multiple homicidal behavior [14]. Indeed, many serial and mass murderers exhibit patient planning and preparation for their crimes. In terms of neurobiological functioning, while there is evidence from Positron Emission Tomography (PET) scans that some violent psychopaths have reduced prefrontal cortical activity, it has been observed that some serial homicide offenders have increased prefrontal cortical activity functioning, which would help account for their careful planning and preparatory behavior [20]. Much more research on core genetic and neurobiological factors associated with multiple homicide, specifically, is warranted.

Some research shows a higher prevalence of Autism Spectrum Disorders (ASD) and childhood head injuries among both serial and mass murderers compared to the general population [21]. Severe real or perceived childhood trauma or neglect is common in the histories of serial murderers [8]. However, there are numerous people who have experienced various neuropsychological issues common to multiple murder, including trauma or neglect, but do not become violent offenders; thus, such conditions may have some influence on pathways to behavior but cannot be said to be causal [14].

Serial homicide offenders can be differentiated according to whether they act alone or as a team, by gender (male or female), or mobility (traveling to commit crimes, killing locally, or murder is restricted to a specific place, such as health care setting) [8]. Although subjective pleasure from having ultimate power over targeted human beings (dictating how, when, and where they die) seems to be the underlying primary theme for killing [22], this is sexualized for many, but not all, serial homicide offenders. Serial sexual murderers tend to isolate and compulsively masturbate to specific paraphilias, which offer temporary relief from their impoverished emotional, interpersonal, and sexual lives [23]. It has been known for decades that serial murderers have detailed fantasies that serve as a blueprint for their violent behavior [24], and some sexual serial murderers seem to rehearse paraphilic elements of fantasy on themselves in preparation to inflict these behaviors on victims [25]. Psychological testing has shown that while many serial homicide offenders have elevated Minnesota-Multiphasic Personality Inventory-2 (MMPI-2) scores on psychopathy, others, surprisingly, do not show strong evidence for psychopathy $[26,27]$. Serial homicide offenders generally have anti-authority attitudes and a willingness to engage in risky behaviors, yet their psychopathological issues are more diverse than would be expected [14,26,27].

In a most general sense, characteristics of mass murder differ based on whether the event took place in a public or private setting [6]. Research has shown that although details vary, the underlying primary motives of mass murder are one or more of the following: revenge (e.g., disgruntled individual who feels extremely victimized and seeks retribution), power (e.g., public massacre as a personal war by a marginalized individual), loyalty (e.g., a devoted parent kills his spouse, children, then himself to spare them all from a bleak future), terror (e.g., an individual kills based on religious or political ideology to instill fear), or profit (e.g., individuals are killed to eliminate witnesses to another crime) [3,9]. A recent study of 318 public mass murders in the United States between 1966 and 2017 found that ideologically motivated offenders were the most patient, methodical, and thus most lethal, compared to other types of public mass violence, whereas disgruntled employee offenders, motivated by revenge, took the least amount of time in planning their attacks [28]. Many public mass murderers have shown signs of trauma, paranoid thinking, and/or psychopathy [29,30]. They harbor feelings of resentment, which increasingly 
intensify and are fueled by violent fantasies reflecting dominant themes of revenge, sadistic payback, escape or temporary refuge, and attention seeking [31,32]. At some point, public mass homicide offenders commit to operationalizing fantasy through planning and preparatory attack behaviors.

Generally, mass murderers show schizoid personality traits $[33,34]$, and due to unfortunate life circumstances and their particular appraisal of such difficulties, they feel hopeless and helpless in multiple aspects of their lives [33-35]. Thus, threat assessments should not only consider social and behavioral problems pertaining to high-risk individuals, but also assess positive factors in a person's life that perhaps can be strengthened in an effort to defer potential violence.

\subsection{Sociological and Demographic Features}

While it is impossible to begin to understand the phenomena of serial and mass murder without a familiarity of relevant psychological issues, forensic behavioral scientists have also pointed out important sociological and demographic features associated with multiple homicide cases. Serial and mass murderers tend to be conservative, come from working or lower-middle classes (and are highly class conscious), and feel prohibited from their desired social groups [36]. Feeling inadequate with their masculinity, these offenders seem to exaggerate common masculine themes-such as worldly ambition, success and failure, and social aggression — present in their culture [36]. Indeed, many public mass murder events are believed to occur due to a complex mix of personal, social, and political forces that crystalize together [34]. Multiple homicide offenders often receive extensive media attention, which can fuel a craving to display personal power through violence against a society in which they feel rejected. Regarding both serial and public mass murder, research has shown that extensive media coverage of such crimes can create copycat effects and lead potentially violent offenders to seek higher numbers of fatalities in their planned attacks [36-38]. These broader factors may at least partly explain differences in prevalence rates of multiple murder across nations, including somewhat high rates (especially serial murder) in the USA [8]. Sociological research on multiple murder calls for increased awareness concerning how drastic changes in economic and political conditions and cultural values, within a given area, may potentially impact rates of extreme violence. Furthermore, sociological and demographic studies on multiple homicide may be most useful to communities in day-to-day risk management, including increasing public safety awareness, improving security measures in high-risk areas, and facilitating logistical preparation and service coordination between public health and law enforcement agencies.

\section{New Behavioral Science Research on Multiple Homicide as Leisure}

Violent crime, according to classical Routine Activities Theory (RAT), occurs based on everyday social and structural features that influence offenders' opportunities to act [39]. Factors such as population density and characteristics and the availability of desired victims naturally create conditions more or less favorable to the commission of violent crime [38,39]. These factors also largely underlie people's day-to-day lifestyles-their work and leisure routines.

It has only been in recent years that scholars began to explore, theoretically and empirically, killing as potential leisure, being reasonably freely chosen and intrinsically motivated, by serial homicide offenders [2,40-42]. Subsequently, initial case studies utilizing content analysis of offender interviews and forensic documents have confirmed that the processes of planning and committing both serial $[43,44]$ and mass murder [45] may be experienced by offenders, not only as the most extreme form of deviant leisure, but are consistent with robust general leisure theories. A subsequent study that examined the potential relevance of leisure across hundreds of serial homicide cases found the emergence of four primary themes: committing murder as a type of game; killing for simple fun and enjoyment; killing for intense thrills and sensations; and committing murder as a form of personal celebration (i.e., on holidays, special occasions) [42].

Flow Theory $(F T)$ is a robust leisure theory showing that optimal, most satisfying, leisure experiences are most likely to occur when there is a near equal balance of skill level and challenge [46]. However, 
when skill level of participants exceeds challenge of the activity, then participants will feel bored; conversely, when challenge exceeds skill, then participants will be frustrated [46]. It is well known among forensic behavioral scientists that serial homicide offenders often feel frustrated with their first murders and that offenders, likely due to their narcissism, take more risks over time. However, FT predicts that the challenge of successfully killing far exceeds offenders' skill during initial homicides, but as offenders' killing skills improve with experience, they must also increase activity challenges in order to attain psychological satisfaction $[2,43]$.

One of the most robust theoretical approaches in leisure sciences is the Serious Leisure Perspective $(S L P)$, which has been addressed by scholars for over 40 years. According to SLP, diverse leisure activities may be classified along a continuum from casual to serious, depending on attributes of the activity, or as one-time or infrequent structured projects [47-49]. Casual leisure activities require little effort or skill and include play, relaxation, passive entertainment, active entertainment, sociable conversation, and sensory stimulation, and benefits are associated with relaxation and stress reduction $[47,50]$. In contrast, serious leisure activities are sufficiently desirable to participants that knowledge and skill acquisition are needed; planning, effort, and perseverance are required; durable benefits and rewards are gained; and a leisure identity around the activity is formed [47-49]. Project-based leisure has some characteristics of both casual and serious leisure; involves participation in planning and executing a one time or infrequent leisure events; but participants have no intention of continuing such participation in a career-like fashion (in contrast to serious leisure) [48,49].

The application of SLP to multiple homicide, then, potentially may provide valuable details into how particular serial and some public mass murderers approach, plan, and commit violent crimes along with specific personal leisure benefits (psychological and social) that occur as a result. Recent research shows that while the homicidal processes of many serial murderers reflect serious leisure to one degree or another, other serial homicide offenders display murder processes that are much more spontaneous and far less complicated, thus reflecting casual leisure [51]. Serial murder as project-based leisure appears to be very rare [43,51], but the structure and desired subjective experience of this form of leisure seems to be applicable to some forms of public mass murder [45]. Research on the application of SLP to different forms of mass murder is in progress by this author [52].

Leisure researchers also explore the barriers to individuals' participation in desired leisure activities. Multiple empirically-driven theories exist that address leisure constraints and negotiation [53]. Generally, levels of constraints are intrapersonal (i.e., personal and psychological features), interpersonal (i.e., relationships and interactions with others), and structural (i.e., lack of money or supplies, natural and social environmental constraints) [53]. Initially, leisure scholars thought that negotiation of constraints was necessarily hierarchical, thus intrapersonal constraints must be negotiated first, then interpersonal, and finally structural constraints. However, numerous studies since have since shown that constraint negotiation for most leisure activities can begin at any level and follow any sequence [53]. In contrast to most leisure activities, when it comes to negotiating constraints to multiple homicide as leisure, research shows that offenders must overcome intrapersonal constraints first, followed by interpersonal, and finally structural constraints [42]. Forensic behavioral science studies show that both serial and mass murderers must rationalize and justify their desired violent actions in various ways $[3,35,54,55]$, which effectively serve to negotiate intrapersonal constraints to their deviant leisure [42]. Put simply, multiple homicide offenders who want to kill for enjoyment or pleasure must first talk themselves into doing so. Additionally, in contrast to typical leisure activities, interpersonal constraints have been found to be simultaneously leisure facilitators with respect to killing [42,45]. For example, several serial homicide offenders have reported wanting to kill more frequently but could not do so because of family, work, and community obligations. However, these same interpersonal roles also allow both serial and mass murderers to plan and execute their crimes without being detected [42,45]. Research suggests that structural constraints, in many cases, may be the easiest level of leisure constraints to overcome for those violent offenders who are willing to take sufficient time to plan and prepare [42]. 


\section{Conclusions}

Forensic behavioral science typically draws from multiple social and behavioral science disciplines, including psychiatry, psychology, and sociology, to help better understand social and behavioral features, dynamics, and processes that contribute to crime. Although serial and mass murder are rare phenomena, these events cause extensive human suffering to victims and widespread fear across populations wherein such events occur. The integrative approach of forensic behavioral science highlights individual, demographic, social and cultural features that are found to be associated with violence, which taken together, offers a more complete understanding of multiple homicide than any single discipline. Although the prevalence of specific forms of multiple homicide varies widely in different nations, it is important for forensic scholars and practitioners to have some familiarity with relevant research, if only for preventive and preparatory purposes.

In recent years, researchers have begun to consider the potential of leisure science in an effort to perhaps better understand multiple homicide cases that are relatively freely chosen and intrinsically motivated. It should be pointed out that social and behavioral scientists of all specializations acknowledge that all humans have various biological, psychological, and social constraints that restrict their choices. However, within such constraints, it is important to understand individuals' decision-making processes and complex motivations that shape their particular choices, including for both crime (for some) and leisure. Although leisure scholarship does not apply to criminal behavior that is primarily extrinsically motivated, it does appear to offer forensic behavioral insights for crimes that are intentionally committed largely for pleasure, fun, thrills, a sense of adventure, and enjoyment $[40,41]$. Because such personal gratification associated with violence is virtually ubiquitous among serial homicide offenders [22,42], it should not be surprising that the application of leisure science to multiple homicide would focus primarily on the phenomenon of serial murder. Such early research has shown promise in getting "inside the minds" of serial murderers [2] to better understand unique features of offenders' homicidal processes that reflect how specific offenders plan and structure their crimes.

Similarly, a leisure approach, particularly SLP and constraints negotiation theories, may offer insights in some cases of public mass murder (as an extreme form of project-based leisure) [45,52]. Furthermore, some public mass murderers as well as serial murderers seem to draw from, or perhaps further develop, already existing leisure preferences that are then incorporated into homicidal activities [44]. Regarding prevention efforts, it may be useful to identify the types and seriousness of high-risk individuals' leisure activities that potentially may be present in homicidal processes. Thus, more studies exploring leisure interests and patterns across the lives of multiple homicide offenders are needed. Regarding private mass murder events, it is possible that some cases, such as a parent who kills the family then him or herself in order to spare the family from a bleak future, may have significant leisure relevance. In other words, such cases potentially may reflect a serious inability to negotiate multiple levels of leisure constraints, thus an envisioned future devoid of pleasure, fun, and happiness-purposeful leisure-underlies the decision to end family misery. If so, helping high-risk individuals negotiate constraints to health-promoting, satisfying leisure experiences may prove valuable in prevention efforts.

To date, precise causes of specific forms of multiple homicide remain elusive. Furthermore, because of the multidimensional (i.e., behavioral genetic, neurobiological, psychological, sociological) features of such crimes, researchers focus on trying to identify potential pathways to such violent events. The addition of recent leisure science research to forensic behavioral science adds a new dimension to understanding some expressive forms of crime. While studies are valuable, much more research is needed to better understand diverse ways that violent offenders begin to formulate, prepare, and carry out their homicidal desires.

Funding: This research received no external funding.

Institutional Review Board Statement: Not applicable. 
Informed Consent Statement: Not applicable.

Data Availability Statement: Data sharing is not applicable to this article.

Acknowledgments: The author extends special thanks to Kaleigh Schaal, Northwestern University (USA), and Michelle Hillman, Idaho State University (USA) for their valuable help collecting data for the author's current research on multiple homicide.

Conflicts of Interest: The author declares no conflict of interest.

\section{References}

1. Walker, G.J.; Scott, D.; Stodolska, M. Leisure Matters: The State and Future of Leisure Studies; Venture Publishing: State College, PA, USA, 2016.

2. Williams, D.J. Entering the minds of serial murderers: The application of forensic leisure science to homicide research. Leis. Sci. 2017, 39, 376-383. [CrossRef]

3. Fox, J.A.; Levin, J. Extreme Killing: Understanding Serial and Mass Murder, 3rd ed.; Sage: Los Angeles, CA, USA, 2015.

4. Adjorlolo, S.; Chan, H.C. The controversy of defining serial murder: Revisited. Aggress. Violent Behav. 2014, 19, 486-491. [CrossRef]

5. Fridel, E.E.; Fox, J.A. Two few victims: Finding the optimal minimum victim threshold for defining serial murder. Psychol. Violence 2018, 8, 505-514. [CrossRef]

6. Huff-Corzine, L.; Corzine, J. The devil's in the details: Measuring mass violence. Criminol. Public Policy 2020, 19,317-333. [CrossRef]

7. Walters, B.K.; Drislane, L.E.; Patrick, C.J.; Hickey, E.W. Serial murder: Facts and misconceptions. In Science and the Courts; National Courts and Science Institute: Washington, DC, USA, 2015.

8. Hickey, E.W. Serial Murderers and Their Victims, 7th ed.; Cengage Learning: Boston, MA, USA, 2016.

9. Fox, J.A.; DeLateur, M.J. Mass shootings in America: Moving beyond Newtown. Homicide Stud. 2014, 18, 125-145. [CrossRef]

10. Duwe, G. Patterns and prevalence of lethal mass violence. Criminol. Public Policy 2020, 19, 17-35. [CrossRef]

11. Lankford, A.; Silver, J. Why have public mass shootings become more deadly? Assessing how perpetrators' motives and methods have changed over time. Criminol. Public Policy 2020, 19, 37-60. [CrossRef]

12. Mellor, L. Rampage: Canadian Mass Murder and Spree Killing; Dundurn: Toronto, ON, Canada, 2013.

13. Crime Prevention Research Center. Available online: https://crimeresearch.org/2015/06/comparing-deathrates-from-mass-public-shootings-in-the-us-and-europe/ (accessed on 9 March 2021).

14. Reid, S. Developmental pathways to serial homicide: A critical review of the biological literature. Aggress. Violent Behav. 2017, 35, 52-61. [CrossRef]

15. Miller, L. Serial killers: I. Subtypes, patterns, and motives. Aggress. Violent Behav. 2014, 19, 1-11. [CrossRef]

16. Miller, L. Serial killers: II. Development, dynamics, and forensics. Aggress. Violent Behav. 2014, 19, 12-22. [CrossRef]

17. Ferguson, C.J.; Beaver, K.M. Natural born killers: The genetic origins of extreme violence. Aggress. Violent Behav. 2009, 14, 286-294. [CrossRef]

18. Iofrida, C.; Palumbo, S.; Pellegrini, S. Molecular genetics and antisocial behavior: Where do we stand? Exp. Biol. Med. 2014, 239, 1514-1523. [CrossRef]

19. Feresin, E. Lighter sentence for murderer with "bad genes". Nature 2009. [CrossRef]

20. Raine, A. The Anatomy of Violence: The Biological Roots of Crime; Random House: New York, NY, USA, 2013.

21. Allely, C.S.; Minnis, H.; Thompson, L.; Wilson, P.; Gillberg, C. Neurodevelopmental and psychosocial risk factors in serial killers and mass murderers. Aggress. Violent Behav. 2014, 19, 288-301. [CrossRef]

22. Reid, S. Compulsive criminal homicide: A new nosology for serial murder. Aggress. Violent Behav. 2017, 34, 290-301. [CrossRef]

23. James, J.; Proulx, J. A psychological and developmental profile of sexual murderers: A systematic review. Aggress. Violent Behav. 2014, 19, 592-607. [CrossRef]

24. Prentky, R.A.; Burgess, A.; Rokous, F.R.; Lee, A.; Hartman, C.; Ressler, R.K.; Douglas, J.E. The presumptive role of fantasy in serial homicide. Am. J. Psychiatry 1989, 146, 887-891. [PubMed]

25. Knoll, J.L.; Hazelwood, R.R. Becoming the victim: Beyond sadism in serial sexual murderers. Aggress. Violent Behav. 2009, 14, 106-114. [CrossRef] 
26. Culhane, S.E.; Hildebrand, M.M.; Walker, S.; Gray, M.J. MMPI-2 characteristics of male serial murderers. Appl. Psych. Crim. Justice 2014, 10, 21-45.

27. Culhane, S.E.; Walker, S.; Hildebrand, M.M. Serial homicide perpetrators' self-reported psychopathy and criminal thinking. J. Police Crim. Psych. 2017, 34, 1-13. [CrossRef]

28. Capellan, J.A.; Johnson, J.; Porter, J.R.; Martin, C. Disaggregating mass public shootings: A comparative analysis of disgruntled employee, school, ideologically motivated, and rampage shooters. J. Forensic Sci. 2019, 64, 814-823. [CrossRef]

29. Langman, P. Rampage school shooters: A typology. Agress. Violent Behav. 2009, 14, 79-86. [CrossRef]

30. Dutton, D.G.; White, K.R.; Fogarty, D. Paranoid thinking in mass shooters. Aggress. Violent Behav. 2013, 18, 548-553. [CrossRef]

31. Murray, J.L. The transcendent fantasy in mass killers. Deviant. Behav. 2017, 38, 1172-1185. [CrossRef]

32. Knoll, J.L. The "pseudocommando" mass murderer: Part I, The psychology of revenge and obliteration. J. Am. Acad. Psychiatry Law 2010, 38, 87-94.

33. Arntfield, M.; Danesi, M. Murder in Plain English: From Manifestos to Memes-Looking at Murder through the Words of Killers; Prometheus: New York, NY, USA, 2017.

34. Gill, P.; Silver, J.; Horgan, J.; Corner, E. Shooting alone: The pre-attack experiences and behaviors of U.S. solo mass murderers. J. Forensic Sci. 2017, 62, 710-714. [CrossRef]

35. Williams, D.J.; Arntfield, M. Extreme sex-negativity: An examination of helplessness, hopelessness, and misattribution of blame among "incel" multiple homicide offenders. J. Posit. Sex. 2020, 6, 33-42. [CrossRef]

36. Leyton, E. Hunting Humans: The Rise of the Modern Multiple Murderer, 2nd ed.; McClelland \& Stewart: Toronton, ON, Canada, 2005.

37. Lankford, A.; Madfis, E. Don't name them, don't show them, but report everything else: A pragmatic proposal for denying mass killers the attention they seek and deterring future offenders. Am. Behav. Sci. 2018, 62, 260-279. [CrossRef]

38. Haggerty, K. Modern serial killers. Crime Media Cult. 2009, 5, 168-187. [CrossRef]

39. Cohen, L.E.; Felson, M. Social change and crime rate trends: A routine activity approach. Am. Sociol. Rev. 1979, 44, 588-608. [CrossRef]

40. Rojek, C. Abnormal leisure: Invasive, mephitic, and wild forms. Soc. Leis. 1999, 22, 21-37. [CrossRef]

41. Williams, D.J.; Walker, G.J. Leisure, deviant leisure, and crime: Caution: Objects may be closer than they appear. Leis. Loisir 2006, 30, 193-218. [CrossRef]

42. Williams, D.J.; Thomas, J.N.; Arntfield, M. An empirical exploration of leisure-related themes and potential constraints across descriptions of serial homicide cases. Leis. Sci. 2020, 42, 69-84. [CrossRef]

43. Williams, D.J. Mephitic projects: A forensic leisure science analysis of the BTK serial murders. J. Forensic Psychi. Psych. 2017, 28, 27-37. [CrossRef]

44. Williams, D.J. Is serial sexual homicide as compulsion, deviant leisure, or both? Revising the case of Ted Bundy. Leis. Sci. 2020, 42, 205-223. [CrossRef]

45. Arntfield, M.; Williams, D.J. An unlikely retirement: The Las Vegas massacre as an exercise in project-based deviant leisure. Homicide Stud. 2018, 22, 410-421. [CrossRef]

46. Csikszentmihalyi, M. Flow: The Psychology of Optimal Experience; Basic Books: New York, NY, USA, 1990.

47. Stebbins, R.A. New Directions in the Theory and Research of Serious Leisure; Edwin Mellen Press: Queenston, ON, Canada, 2001.

48. Stebbins, R.A. Serious Leisure: A Perspective for Our Time; Transaction: New Brunswick, NJ, USA, 2015.

49. Stebbins, R.A. Project-based leisure: Theoretical neglect of a common use of free time. Leis. Stud. 2005, 24, 1-11. [CrossRef]

50. Stebbins, R.A. The costs and benefits of hedonism: Some consequences of taking casual leisure seriously. Leis. Stud. 2001, 20, 305-309. [CrossRef]

51. Williams, D.J.; Vincent, J. Application of the Serious Leisure Perspective to intrinsically motivated serial homicide. Deviant Behav. 2019, 40, 1057-1067. [CrossRef]

52. Williams, D.J.; Schaal, K. Can mass violence be planned as ultimate leisure experience? Analysis of three cases. J. Forensic Sci.. under review. 
53. Schneider, I. Leisure constraints and negotiation: Highlights from the Journey Past, Present and Future. In Leisure Matters: The State and Future of Leisure Studies; Walker, G.J., Scott, D., Stodolska, M., Eds.; Venture Publishing: State College, PA, USA, 2016; pp. 151-161.

54. James, V.; Gossett, J. Of monsters and men: Exploring serial murderers' discourses of neutralization. Deviant Behav. 2018, 39, 1120-1139. [CrossRef]

55. Coston, C.T.M. Self-report justifications for serial sex murder: An exploratory study of neutralization techniques. SAJ Forensic Sci. 2015, 1, 1-6.

Publisher's Note: MDPI stays neutral with regard to jurisdictional claims in published maps and institutional affiliations.

(C) 2021 by the author. Licensee MDPI, Basel, Switzerland. This article is an open access article distributed under the terms and conditions of the Creative Commons Attribution (CC BY) license (http://creativecommons.org/licenses/by/4.0/). 